OPEN ACCESS

Edited by:

Daohong Zhang,

Northwest $A$ and $F$ University, China

Reviewed by:

Chenglong $\mathrm{Li}$,

Henan Agricultural University, China

Nan Hao,

Jiangsu University, China

*Correspondence:

Mingzhou Zhang

zmzcjlu@cjlu.edu.cn

${ }^{+}$These authors have contributed equally to this work

Specialty section: This article was submitted to Analytical Chemistry, a section of the journal

Frontiers in Chemistry

Received: 12 October 2021 Accepted: 29 November 2021 Published: 20 December 2021

Citation:

Wang Y, Ma B, Liu M, Chen E, Xu Yand Zhang M (2021) Europium Fluorescent Nanoparticles-Based Multiplex Lateral Flow Immunoassay for Simultaneous Detection of Three Antibiotic Families Residue.

Front. Chem. 9:793355. doi: 10.3389/fchem.2021.793355

\section{Europium Fluorescent} Nanoparticles-Based Multiplex Lateral Flow Immunoassay for Simultaneous Detection of Three Antibiotic Families Residue

\author{
Yaping $\mathrm{Wang}^{\dagger}$, Biao $\mathrm{Ma}^{\dagger}$, Miaomiao Liu, Erjing Chen, Ying Xu and Mingzhou Zhang * \\ Zhejiang Provincial Key Laboratory of Biometrology and Inspection and Quarantine, China Jiliang University, Hangzhou, China
}

A fluorescent immunoassay based on europium nanoparticles (EuNPs-FIA) was developed for the simultaneous detection of antibiotic residues, solving the problems of single target detection and low sensitivity of traditional immunoassay methods. In the EuNPs-FIA, EuNPs were used as indictive probes by binding to anti-tetracyclines monoclonal antibodies (anti-TCs mAb), anti-sulphonamides monoclonal antibodies (anti-SAs mAb) and anti-fluoroquinolones monoclonal antibodies (anti-FQs mAb), respectively. Different artificial antigens were assigned to different regions of the nitrocellulose membrane as capture reagents. The EuNPs-FIA allowed for the simultaneous detection of three classes of antibiotics (tetracyclines, fluoroquinolones and sulphonamides) within $15 \mathrm{~min}$. It enabled both the qualitative determination with the naked eye under UV light and the quantitative detection of target antibiotics by scanning the fluorescence intensity of the detection probes on the corresponding detection lines. For qualitative analysis, the cut-off values for tetracyclines (TCs), fluoroquinolones (FQs) and sulphonamides (SAs) were $3.2 \mathrm{ng} / \mathrm{ml}, 2.4 \mathrm{ng} / \mathrm{ml}$ and $4.0 \mathrm{ng} /$ $\mathrm{ml}$, respectively, which were much lower than the maximum residue limit in food. For quantitative analysis, these ranged from 0.06 to $6.85 \mathrm{ng} / \mathrm{ml}$ for TCs, $0.03-5.14 \mathrm{ng} / \mathrm{ml}$ for FQs, and $0.04-4.40 \mathrm{ng} / \mathrm{ml}$ for SAs. The linear correlation coefficients were higher than 0.97. The mean spiked recoveries ranged from 92.1 to $106.2 \%$ with relative standard deviations less than $8.75 \%$. Among them, the three monoclonal antibodies could recognize four types of TCs, seven types of FQs and 13 types of SAs, respectively, and the detection range could cover 24 antibiotic residues with different structural formulations. The results of the detection of antibiotic residues in real samples using this method were highly correlated with those of high performance liquid chromatography $\left(R^{2}>0.98\right)$. The accuracy and precision of the EuNPs-FIA also met the requirements for quantitative analysis. These results suggested that this multiplex immunoassay method was a promising method for rapid screening of three families of antibiotic residues.

Keywords: sulfonamide antibiotics, tetracycline antibiotics, fluoroquinolone antibiotics, europium nanoparticle fluorescence immunochromatography, multi-residue detection 


\section{INTRODUCTION}

Since the discovery of penicillin in 1929, antibiotics were frequently used as clinical agents to prevent and treat bacterial infections in human and veterinary medicine (Kong et al., 2020). Effective antibiotics were the cornerstone of modern medicine supporting organ transplants, surgical prophylaxis, protecting newborns from septic infections and avoiding infections during cancer chemotherapy. Unfortunately, the excessive and indiscriminate use of antibiotics in interconnected ecosystems around the world had led to a dramatic rise in drug resistance. This concern had been listed by the World Health Organisation as one of the top ten public health threats (Anita et al., 2021). A number of veterinary antibiotics, including tetracyclines (TCs), fluoroquinolones (FQs) sulphonamides (SAs) and macrolides (MLs), were used to improve feed efficiency and promote growth rates. Approximately $30-90 \%$ of consumed antibiotics were excreted in urine and faeces as parent compounds and/or metabolites. In addition, $70-80 \%$ of the antibiotics used in animal feeding also end up in food due to incomplete removal of antibiotics (Ben et al., 2019). Prolonged exposure of microorganisms to such conditions could transform them into "superbugs". This places a heavy burden on the global economy. It is estimated that by 2050 some 4.44 million people would be affected by infections that would not receive effective treatment (Chen Y. et al., 2020). The overuse of antibiotics in interconnected ecosystems had led to their presence in a variety of environmental matrices, even in the food chain, which had posed a growing threat to public health safety. For example, antibiotics could modulate human mood and increase the risk of depression (mental illness) by altering the gut microbiota and brain-gut axis (Konstantinidis et al., 2020). It may also induce a range of genetic effects in humans, such as carcinogenic or allergic reactions (Li et al., 2020).

SAs, FQs, and TCs were common food contaminants that were often left in foods such as eggs, milk, chicken and honey (Zou et al., 2019), posing a concerted threat to human health. Excess antibiotics accumulate in the body through food, causing dysbiosis in the human intestinal flora, leading to increased bacterial resistance even cancer in various tissues and organs (Hoffmann et al., 2016). Many countries and government organisations had set maximum residue limits (MRLs) for most antibiotics in different animal foods (Yong et al., 2018). For example, the Ministry of Agriculture of the People's Republic of China has announced that the MRL for SAs, TCs, and FQs in milk were 25, 100, and $100 \mathrm{ng} / \mathrm{ml}$ (GB31650-2019, 2019). Therefore, it was particularly important to test for residues of antibiotics in food. As the number of controlled compounds in medical diagnostics increases (Rashid et al., 2020), food safety and ecological monitoring due to the choice of multiple antibiotics mixed to achieve the desired effect when faced with disease treatment and prevention led to the need for multiple testing systems to ensure public environmental safety (Yi et al., 2016). The increase in health risk factors had placed new demands on analytical methods for medical diagnostics, environmental monitoring and food quality control. In these areas, it was important to be able to monitor the levels of several antibiotics in the same sample simultaneously and to obtain test results in a short time with minimal labour (Jin et al., 2020). However, the application of europium fluorescent labelling for the simultaneous detection of multiple antibiotics had been rarely reported. In recent years, various methods had been developed for the detection of ciprofloxacin (El Kojok et al., 2020), tetracycline (Xu et al., 2020) and sulfadimethoxine (Yan et al., 2017) in food, but the detection targets were single and the sensitivity was not satisfactory (Chen Y. et al., 2020). In a global study (Amy et al., 2020), the presence of three and more different species of antibiotic residues could be detected simultaneously in different environmental matrices in 47 countries worldwide, with TCs, SAs, and FQs accounting for a large proportion of these residues (Chen $\mathrm{H}$. et al., 2020). Therefore, the detection of a single type of antibiotic residue was no longer sufficient to ensure the safety of the public living environment.

With increasing concern for environmental quality and public health (Zhang et al., 2020) real-time monitoring of antibiotic residues in the aquatic environment is essential (Yang et al., 2020). There were many methods for screening antibiotic residues (Zhen et al., 2011), including chromatography, microbiological assay and immunoassay (Wang et al., 2019). Although the microbiological method was simple and convenient, the specificity was relatively low, and it required time-consuming sample processing steps (Wang et al., 2019). Chromatographic methods, such as high performance liquid chromatography (HPLC) (Soh et al., 2020), capillary electrophoresis (CE) (Asha et al., 2020), mass spectrometry (MS) (Abafe et al., 2020) are characterized by high sensitivity and reliability. However, special laboratories with expensive equipment and high-quality personnel were demanded. Obviously, the application of these methods in on-site detection of antibiotic residues in food was limited (Suo et al., 2019).

In addition, there are many immunoassays in use, such as radioimmunoassay (RIA) (Zhou et al., 2014), flow injection chemiluminescence with immunoassay (FICLIA) (Yuan et al., 2017), colloidal gold immunoassay (GIA) and enzyme-linked immunoassay (ELISA) (Song et al., 2018). Among these, ELISA was used as a validated immunoassay for screening a large number of samples. However, enzyme-linked immunosorbent assay still needs complicated and precise laboratory operations, such as multiple incubation, washing and sample pretreatment steps, which hinders its application in society and market (Lin et al., 2019). In resource-poor areas, lateral flow immunoassay strips (De et al., 2020), were more feasible than ELISA. It had been widely used for screening veterinary drug residues in food because of their unique advantages of rapidity, simplicity, stability and portability as an alternative choice to ELISA in essential sites (Chen H. et al., 2021) and had been widely used for screening veterinary drug residues in food (Ling et al., 2019). Among them, the commonly used colloidal gold immunoassay had limited its wide application in production and development due to matrix effect and low sensitivity (Liang et al., 2019; Marjan et al., 2019). In order to improve the sensitivity and specificity of the method for quantitative and multi-drug residue detection, some new immune-chromatographic detection methods have 
gradually highlighted their unique advantages in residue detection (Ben et al., 2019).

As an alternative to colloidal gold, fluorescent markers such as quantum dots, fluorescent nanosilica, fluorescent beads and lanthanides have been widely used in immunochromatographic methods (Wei et al., 2019). As the excitation and emission wavelengths of most fluorescent markers are in the ultraviolet-visible (UV-vis) wavelength range, membrane supports, biological components etc. generate high fluorescence background interference due to light scattering and autofluorescence (Castillo-García et al., 2015). The advantage of the strong signal intensity contributed by these fluorescent markers is therefore diminished by their high fluorescence background (Ye et al., 2020). The lanthanides (Wang et al., 2020), europium (Eu) (II), terbium (Tb) (II), samarium (Sm) (II) and dysprosium (Dy) (III), were of interest because of their long fluorescence lifetimes and large Stokes shifts (Chen $\mathrm{H}$. et al., 2020), which help to reduce the interference of fluorescence background signals and improve sensitivity. It can be seen that lanthanide-europium was already used for the detection of streptomycin in milk (Anastasiya et al., 2020), however, the detection was limited by the single target.

In this study, we introduced a europium nanoparticle-based fluorescent immunoassay technique (EuNPs-FIA) for the simultaneous determination of tetracyclines, fluoroquinolones, and sulphonamides antibiotics in food. The problem of single detection target and low sensitivity was solved. Three populationspecific monoclonal antibodies were developed to increase the number of tests. The three monoclonal antibodies could recognize four types of TCs, seven types of FQs and 13 types of SAs, respectively, and the detection range could cover 24 antibiotic residues with different structural formulations. Together with the advantage that the lateral flow immunoassay strips can be easily manipulated, it makes the whole assay system of great potential for quality control and detection of drug residues.

\section{MATERIALS AND METHODS}

\section{Reagents}

Tetracycline (TC), Chlortetracycline (CTC), Oxytetracycline (OTC), Doxycycline (DOX), Enrofloxacin (ENR), Ciprofloxacin (CIP), Ofloxacin (OFL), Lomefloxacin (LOM), Dalflo-xacin (DAL), Norfloxacin (NOR), Difluoxacin (DIF), Sulfamethoxypyridazine (STD), Sulfisoxazole (SXZ), Sulfamethoxypyrimidine (SFM), Sulfathiazole (SFZ), Sulfaquinoxaline (SFX), Sulfapyridine (SFD), Sulfamethoxazole (SMA), Sulfaclozine (SFO), Sulfadimethoxypyrimidine (SMD), Sulfamethoxypyrimidine (STM), Sulfamethoxypyrimidine (SPM), Sulfadimethoxypyrimidine (SMM) and Sulfadiazine (SMZ) were purchased from the National Institute of Metrology, P. R. China (Beijing, China). 1-(3dimethylaminopropyl)-3-ethylcarbodiimide (EDC), N-hydroxysuccinimide (NHS), 2-(N-Morpholino) ethanesulfonic acid (MES) were obtained from Sigma-Aldrich (St. Louis, MO, United States). Bovine serum albumin (BSA), human serum albumin (HAS), were purchased from SinoAmerican Biotechnology (Luoyang, Henan, China). Enzyme immunoassay-grade horseradish peroxidase-labeled goat antimouse immunoglobulin, freund's complete and incomplete adjuvant was purchased from Aladdin Industrial Corporation (Shanghai, China). Nitrocellulose (NC) membrane, sample pad, conjugate pad and absorbent pad were obtained from Dean Biotechnology Co, Ltd (Hangzhou, Zhejiang, China).

Phosphate buffer solution (PBS, $0.01 \mathrm{M}, \mathrm{pH}$ 7.4) was prepared by weighing $0.4 \mathrm{~g} \mathrm{NaCl}, 3.1 \mathrm{~g}$ disodium hydrogen phosphate and $0.5 \mathrm{~g}$ dipotassium hydrogen phosphate dissolved in ultrapure water and fixed to a final volume of $2 \mathrm{~L}$, followed by adjustment of $\mathrm{pH} 7.4$ with sodium hydroxide. Borate buffer solution (BBS, $0.05 \mathrm{M}, \mathrm{pH}$ 8.2) was prepared by weighing $1.68 \mathrm{~g}$ boric acid and $1.34 \mathrm{~g} \mathrm{NaB}_{4} \mathrm{O}_{7-} 10 \mathrm{H}_{2} \mathrm{O}$ was dissolved in ultrapure water, $100 \mu \mathrm{l}$ of $1 \%$ Tween-20 solution was added and the final volume was fixed to a final volume of $2 \mathrm{~L}$ to prepare a borate buffer solution containing $0.05 \%$ (v/v) Tween-20. Carbonate buffer solution (CBS, $0.1 \mathrm{M}, \mathrm{pH}$ 9.6), $3.18 \mathrm{~g}$ $\mathrm{Na}_{2} \mathrm{CO}_{3}$ and $5.88 \mathrm{~g}$ sodium bicarbonate were weighed, dissolved in ultrapure water and allowed to reach a final volume of $2 \mathrm{~L}$. MES buffer solution (0.05 M, pH 6.5), $9.76 \mathrm{~g}$ MES was weighed, dissolved in ultrapure water and allowed to reach a final volume of $1 \mathrm{~L}$, then adjusted with $\mathrm{NaOH}(\mathrm{pH} 6.5)$.

\section{Instruments}

The role of the Hitachi F-4500 fluorescence spectrometer system (Hitachi, Tokyo, Japan) was used to read and record the fluorescence pattern. An XYZ3000 dispensing platform and a CM2000 guillotine cutter (BioDot, Irvine, CA, United States) was used to prepare and cut test strips. The purpose of the FIC-S2011B14 fluorescent strip reader (Suzhou, Jiangsu, China) was used to read and record the results of the fluorometric test strip assay. Agilent 1,100 high performance liquid chromatography system (Agilent Tech, Santa Clara, CA, United States) was used to monitor the results of validated fluorescent test strips.

\section{Synthesis of Artificial Antigens and Immunogens}

Based on previous work in our laboratory (Gong et al., 2014), the parent nucleus structures of sulphonamide antibiotics, tetracycline antibiotics and fluoroquinolone antibiotics were selected as antigens to obtain immunogenicity by binding to carrier proteins. TCs and SAs were synthesised as artificial antigens using a diazotization method, whereby the amino group on the parent nucleus structure was activated using sodium nitrite, and the antigens were then bound to BSA and HSA to prepare immunogen. For FQs, the carboxyl group on the parent nucleus was activated using EDC/NHS and the antigen was bound to BSA and HSA to produce the immunogen and artificial antigen. SDS-PAGE electrophoresis and UV-Vis were used to identify the couples and to evaluate the coupling process.

\section{Preparation of Monoclonal Antibody}

$\mathrm{Bal} / \mathrm{c}$ female mice were selected as immune animals to produce antibodies. In short, each mouse was subcutaneously injected 
with $100 \mu \mathrm{g}$ of immunogen HSA-SAs, HSA-TCs and HSA-FQs emulsified with freund's complete adjuvant, respectively, once a week. After 4 weeks, the immunization was strengthened, each mouse was subcutaneously injected with $50 \mu \mathrm{g}$ of immunogen emulsified with freund's incomplete adjuvant. After three times of immunization, the mouse serum was analyzed and identified by ELISA using homologous and heterologous coated antigens. When the serum titer reached the highest, the mouse spleen with the lowest serum titer and lowest half-maximal inhibitory concentration $\left(\mathrm{IC}_{50}\right)$ value was taken out, and the spleen cells were fused with Sp2/0 myeloma cells. $96 \mathrm{~h}$ before cell fusion, the last spleen shock was performed. After cell fusion, hybridoma cell lines secreting anti-SAs, TCs and FQs monoclonal antibody was screened out by selective medium respectively, and the three cell lines were subcloned three times respectively, and the results of each subclone were identified by ELISA (Gong et al., 2014). Screening the best cell line, injecting the best cell line into the abdominal cavity of mice perfused with paraffin to produce ascites, finally purifying the ascites by saturated ammonium sulfate method to obtain anti-SAs, anti-TCs and anti-FQs monoclonal antibody respectively, measuring the antibody concentration by UV-Vis, and storing at $-20^{\circ} \mathrm{C}$.

\section{Preparation of EuNPs-mAb Probes}

Add $3 \mathrm{mg}$ carboxylated europium and $45 \mu \mathrm{lEDC}(10 \mathrm{mg} / \mathrm{ml})$ to $1,200 \mu \mathrm{L}$ MES solution ( $0.05 \mathrm{M}, \mathrm{pH}$ 6.5), and activated by incubation at room temperature on a shaker at $200 \mathrm{rpm} / \mathrm{min}$ for $30 \mathrm{~min}$. The activated product solution was centrifuged at $15,000 \mathrm{rpm}$ for $20 \mathrm{~min}$. After separating additional EDC, the precipitate was redissolved in $500 \mu \mathrm{l}$ BBS (0.05 M, pH 8.0) solution. The solution was divided into fifteen aliquots and $1 \mathrm{ml}$ of anti-FQs mAb at concentrations of $1,2.5,5,15$ and $20 \mu \mathrm{g} / \mathrm{ml}, 1 \mathrm{ml}$ of anti-TCs mAb at concentrations of 2.5, 5, 10, 20 and $30 \mu \mathrm{g} / \mathrm{ml}$ and $1 \mathrm{ml}$ of anti-SAs $\mathrm{mAb}$ at concentrations of 10 , $15,20,25$ and $30 \mu \mathrm{g} / \mathrm{ml}$ were added, respectively and incubated with shaking at room temperature for $2 \mathrm{~h}$. At the end of the reaction, $55 \mu \mathrm{l} 10 \% \mathrm{BSA}(\mathrm{w} / \mathrm{v})$ was added to continue shaking incubation for $2 \mathrm{~h}$, respectively. The excess antibody and BSA were separated by centrifugation three times at $15,000 \mathrm{rpm} / \mathrm{min}$, $10 \mathrm{~min}$. At last, the precipitate was dissolved in $500 \mu \mathrm{lBBS}(0.05$ $\mathrm{M}, \mathrm{pH} 8.0)$ containing $0.1 \% \mathrm{BSA}(\mathrm{w} / \mathrm{v})$, and stored at $4^{\circ} \mathrm{C}$ until further use.

\section{Assembly of Immunochromatographic System}

The immunochromatographic test strip consists of four parts, namely, an absorption pad, a binding pad, a sample pad and a nitrocellulose membrane, which are sequentially assembled on a backing card, and all components are assembled with the back plate overlapped by $2 \mathrm{~mm}$. Sample pad was soaked in PBS buffer solution (0.01 M, pH 7.4) containing $1 \% \mathrm{BSA}(\mathrm{w} / \mathrm{v})$ and $0.05 \%$ Tween-20 (v/v), then dried overnight in a drying oven at $37^{\circ} \mathrm{C}$ and stored in a sealed bag with desiccant for later use. The nitrocellulose membrane was soaked in PBS buffer solution (0.01 $\mathrm{M}, \mathrm{pH}$ 7.4), dried at $37^{\circ} \mathrm{C}$ for $12 \mathrm{~h}$, and then dried for storage. SAsBSA, FQs-BSA, TCs-BSA and goat anti-mouse IgG (GAM-IgG) were sprayed on the $\mathrm{T}$ and $\mathrm{C}$ lines of the nitrocellulose membrane respectively. The labelled monoclonal antibodies against TCs, FQs and SAs were diluted in BBS buffer (0.05 M, pH 8.2, containing $8 \%(\mathrm{w} / \mathrm{v})$ sucrose and $1 \%(\mathrm{w} / \mathrm{v})$ BSA) respectively. They are sprayed separately on the bonding pad. The scratched nitrocellulose membrane were dried overnight at $37^{\circ} \mathrm{C}$. After the above components are processed, they can be assembled into a complete immunochromatographic system, which is cut into $2.5 \mathrm{~mm}$ test strips and dried and stored at room temperature for later use.

\section{Optimisation of Parameters for Single-Component Immunochromatography Systems}

Based on the influence of various factors on the fluorescence intensity and sensitivity of the test results, several key parameters were optimized systematically, including the concentration of EuNPs labeled monoclonal antibody, the probe addition volume, artificial antigen encapsulation concentration and GAM-IgG encapsulation concentration, so as to obtain higher sensitivity and fluorescence signal intensity.

The membrane concentration of SAs-BSA and goat antimouse horseradish peroxidase was optimized from $0,0.2,0.4$, $0.6,0.8,1.0 \mathrm{mg} / \mathrm{ml}$ and $0,0.5,1.0,1.0,2.0,2.5 \mathrm{mg} / \mathrm{ml}$ respectively.

After optimizing the above variable conditions, the fluorescent probes with the concentrations of $2,4,6$, and $8 \mathrm{ng} / \mathrm{ml}$ were dripped into the test strips, and the optimal amount of probes was screened by detecting the fluorescence intensity of $\mathrm{C}$ line and $\mathrm{T}$ line.

Similar parameter optimisation was carried out for single test strips of FQs and SAs.

\section{Optimization of the \\ Multi-Immunochromatographic System}

Based on the optimised parameters of the single immunoassay system, The parameters of the triple fluorescence immunochromatography system, such as artificial antigen scribe position, encapsulation concentration and GAM-IgG encapsulation concentration, were optimised by orthogonal test L9 (3) ${ }^{3}$ analysis.

At $5,10,15,20,25,30,35$, and 40 min after the start of the reaction, the fluorescence intensity of the $\mathrm{C}$-line and $\mathrm{T}$-line of the test strip was detected, and the optimal reaction time was screened by comparison.

\section{Specificity and Sensitivity Assessment}

The cross-reactivity (CR) and the limit of detection (LOD) were used as quantitative parameters to measure the specificity and sensitivity of this immunochromatographic system. A calibration curve was constructed by plotting the ratio of the fluorescence intensity of spiked and blank samples $\left(\mathrm{B} / \mathrm{B}_{0}\right)$ against the logarithmic concentration of the analyte.

Under optimised conditions, fixed concentrations of mixed standard solutions were prepared by adding each type of antibiotic drug to the buffer solution, and the standard curve 
was established by testing a series of these solutions and reading the values through a fluorescence reader.

The standard curve was obtained by plotting the logarithm of the optical density or fluorescence intensity (Y) versus the concentration of the analyte (X) and fitted to a linear equation. The linear range for this analysis was set at the concentration that results in $10-80 \%$ inhibition.

Standard solutions of 13 types of SAs were diluted to a final concentration of $500 \mathrm{ng} / \mathrm{ml}$ and tested separately against a single sulphonamide immunochromatographic system. Standard solutions of seven types of FQs were diluted to a final concentration of $500 \mathrm{ng} / \mathrm{ml}$ and tested separately on a single fluoroquinolone immunochromatographic system. Standard solutions of four types of TCs were diluted to a final concentration of $500 \mathrm{ng} / \mathrm{ml}$ and tested separately on a single tetracycline immunochromatographic system. The specificity of the triple immunochromatographic system was assessed by testing each analyte individually to exclude false positive results, using the respective mixtures as reference analytes.

\section{Spiked Recovery Tests and Analysis of Actual Samples}

To assess the reliability of the developed test strips, spiked samples in the concentration range of $0.1-2.4 \mathrm{ng} / \mathrm{ml}$ were prepared by adding three representative antibiotic drug standards to a blank negative aqueous solution under optimised conditions and analysed for identification using the EuNPs-FIA developed in the above text.

In order to verify the practical applicability of EuNPs-FIA, four types of actual samples, including honey, milk, chicken and eggs, were selected for analysis. The samples were pre-treated with reference to other methods (Anastasiya et al., 2020).

Chopped chicken was homogenized at 10,000 r/min for $1 \mathrm{~min}$ $1.0 \mathrm{~g}$ of homogenate was weighed into a $15 \mathrm{ml}$ centrifuge tube and $5 \mathrm{ml}$ of acetonitrile was added. The mixture was vortexed and shaken for $5 \mathrm{~min}$ and centrifuged at $4,000 \mathrm{r} / \mathrm{min}$ for $5 \mathrm{~min}$ at room temperature. $1.5 \mathrm{ml}$ of supernatant was transferred to a $5 \mathrm{ml}$ centrifuge tube and dried under nitrogen at $55^{\circ} \mathrm{C}$. Then $1 \mathrm{ml}$ of hexane was added to the residue. Vortex for $30 \mathrm{~s}$ and then add $1 \mathrm{ml}$ of PBS. The lower liquid phase was collected by centrifugation and filtered through a $0.22 \mu \mathrm{m}$ filter for detection. A solution of $950 \mu \mathrm{l}$ could be collected and $40 \mu \mathrm{l}$ was the loading volume for 1strip. The pre-treatment process was similar for chicken and honey. Weigh $1.0 \mathrm{~g}$ of honey into a $15 \mathrm{ml}$ centrifuge tube. Add $5 \mathrm{ml}$ of acetonitrile. Vortex and shake the mixture for $5 \mathrm{~min}$. The next steps were the same as for the chicken. The pre-treatment process for the eggs was slightly different. After shelling the eggs, homogenise at $500 \mathrm{r} /$ min for $20 \mathrm{~s}$ to mix the whites and yolks. $1.0 \mathrm{~g}$ of homogenate was accurately weighed and placed in a centrifuge tube. Then, $2 \mathrm{ml}$ of PBS was added and the homogenate was shaken gently by hand for $20 \mathrm{~min}$. After centrifugation at $4,000 \mathrm{r} / \mathrm{min}$ for $10 \mathrm{~min}$ at room temperature, the supernatant was collected and passed through a $0.22 \mu \mathrm{m}$ filter for detection. A solution of $1.95 \mathrm{ml}$ can be collected and $40 \mu \mathrm{l}$ was the loading volume for
1 strip. The pre-treatment process for milk samples was the simplest. The milk sample was diluted five times directly using PBS solution for the assay. $40 \mu \mathrm{l}$ was the loading volume for 1 strip.

All actual samples were analyzed and confirmed by high performance liquid chromatography (HPLC). The detection of that actual sample were achieved using $0.08 \%$ acetic acid in Milli$\mathrm{Q}$ water, methanol, and acetonitrile with a gradient elution and a Zorbax Eclipse XDB C18 chromatographic column. The flow rate was $0.6 \mathrm{ml} / \mathrm{min}$, and the injection volume was $40 \mu \mathrm{l}$. The column temperature was $25^{\circ} \mathrm{C}$.

\section{Data Analysis}

The peaks of the fluorescence spectra required in the text were analysed using Origin 9 software (Origin Lab, United States). Graphs such as standard curves were plotted using Microsoft Excel software (Microsoft Corporation, United States) for analysis. Schematics of the test strips were drawn using Photoshop software (Adobe Systems, United States).

\section{RESULTS AND DISCUSSION}

\section{Detection Process of Immunochromatographic System}

The detection principle of immunochromatography system was based on the competitive reaction theory (Gong et al., 2014), the principle is based on the competition between target detectors contained in the detection sample and artificial antigen conjugates fixed on nitrocellulose membrane, so as to bind to the monoclonal antibody labeled by EuNPs (Figure 1). Three different antigens were coated on nitrocellulose membranes at different locations to act as capture reagents. Three different monoclonal antibodies labelled with EuNPs were immobilised on the binding pad as detection probes. Drop the sample solution mixed with target analyte onto the sample pad. Under the capillary force, the solution flows to the other side. When flowing through the $\mathrm{T}$ line, a competitive reaction occurs. When the monoclonal antibodies labelled by EuNPs bind to the target analyte in the sample, would cross over to the artificial antigen on the $\mathrm{T}$-line and instead binding to and accumulating goat anti-mouse IgG on the C-line (Figures 1A,B). On the contrary, when the sample solution does not contain the target analyte, the monoclonal antibody labeled by EuNPs reacted with artificial antigen on T-line and goat anti-mouse IgG on C-line (Figure 1C). The fluorescence intensity on the test strip is read and stored by portable reader. If the test procedure is performed correctly, the control line will always be visualised. For qualitative analysis, the fluorescence image was visually inspected to determine the result, while for quantitative analysis, a standard curve is constructed by plotting the ratio between the fluorescence intensity $\left(\mathrm{B} / \mathrm{B}_{0}\right)$ of the spiked and blank samples against the log concentration of the antibiotic residue. The fluorescence intensities of the unknown samples were then brought into the respective calibration curves for calculation to determine the analyte concentrations (Figure 1D-F). 


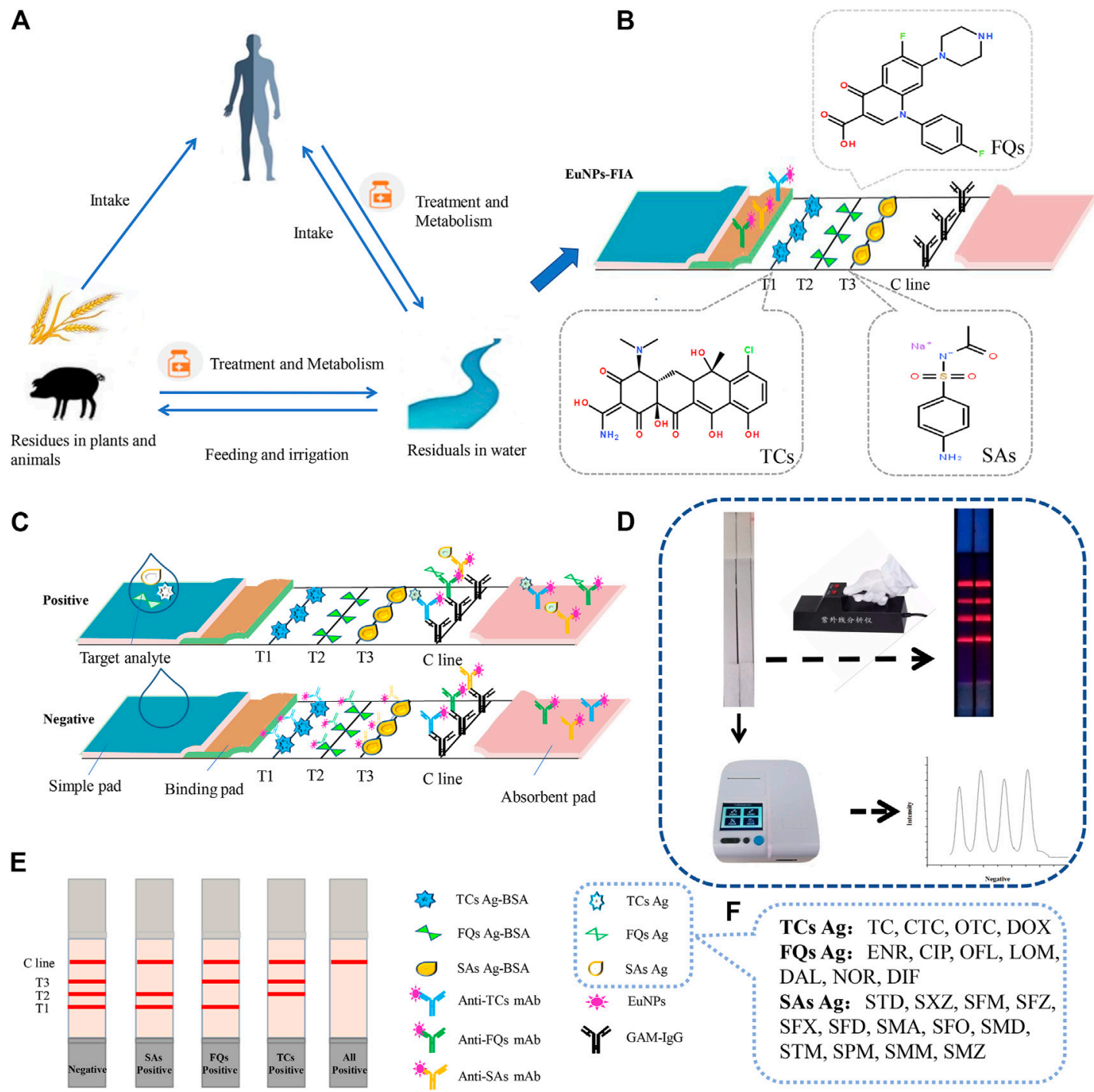

FIGURE 1 | The EuNPs-FIA detection principle. (A) The cycle of antibiotics between man and nature. (B) Principle of assemble EuNPs-FIA test strips. (C) Test results of the EuNPs-FIA reader test results. (D) The actual testing process and test results of the EuNPs-FIA reader test results. (E) Diagram of the test results. (F) Number of detectable target species.

\section{Evaluation of Artificial Antigens and Monoclonal Antibodies}

In order to obtain population-specific monoclonal antibodies that were effective against each antibiotic family, the synthesis of semiantigens was essential (Lin et al., 2010).

The fluoroquinolone antibiotics were chosen to introduce a fluorine atom in the 6 position and a structure with a basic piperazine substituent replaced at the 7 position in pirimicarbazide as the parent nucleus structure, which was linked to the carrier proteins bovine serum albumin and HSA using the carbodiimide method to prepare the artificial antigen (Supplementary Figure S1).

The recognition of members of the sulfonamides family should be based on the common aminobenzensulfonylamino moiety structure. Sulphonamide antibiotics have a similar parent nucleus structure and different $\mathrm{R}$ groups. The $\mathrm{R}$ groups can be broadly classified into two categories:five-membered heterocycles and six-membered heterocycles. Sulfadimethoxine contains only the normal aminobenzenesulfonamide structure without any $\mathrm{R}$ groups. Therefore, it was chosen as the parent structure of the sulphonamide antibiotic and the artificial antigen was prepared by linking it to the carrier proteins bovine serum albumin and HSA using the N-hydroxysuccinimide activated ester method (Supplementary Figure S2).

The common structure of tetracycline antibiotics was the tetraphenyl tetracyclic skeleton, all containing phenolic hydroxyl, enol hydrocarbon and dimethylamine groups. This structure was chosen as the parent nucleus structure of tetracycline antibiotics and the artificial antigen was prepared by linking it to the carrier proteins bovine serum albumin and 

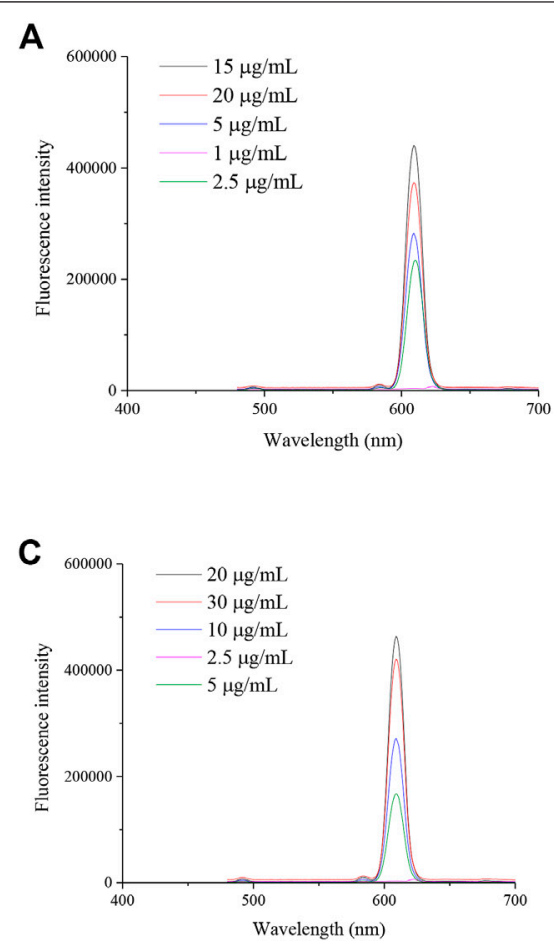

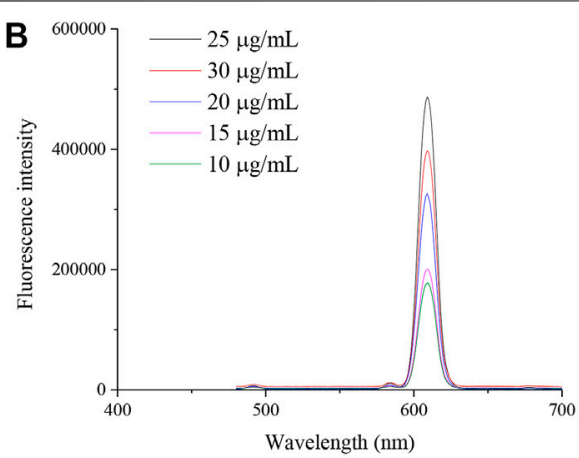

D

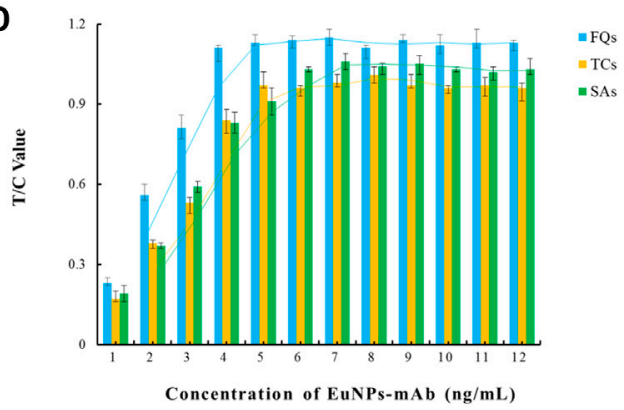

FIGURE 2 | Optimisation of EuNPs-antibody conjugates. (A) Effect of the amount of FQs-mAb labelling on the detection capability of the probe. (B) Effect of the amount of SAs-mAb labelling on the detection capability of the probe. (C) Effect of the amount of TCs-mAb labelling on the detection capability of the probe. (D) Effect of probe incorporation on the detection capacity of single-EuNPs-FIA.

HSA using the N-hydroxysuccinimide activated ester method (Supplementary Figure S3).

The SDS-PAGE identification results indicated successful artificial antigen coupling (Supplementary Figure S1-S3).

After cell fusion, the immunised mice produced ascites. The antibodies purified from ascites were identified and evaluated by enzyme-linked immunosorbent chromatography, and the respective antibody with the highest activity was selected (Supplementary Figure S4). Cross-reactivity tests between these three antibodies and other antibiotics of the same class showed good selectivity (Supplementary Table S1-S3). SAs$\mathrm{mAb}$, FQs-mAb and TCs-mAb could identify 13 classes of SAs, seven classes of FQs and four classes of TCs respectively, enabling the simultaneous detection of the same class of antibiotics on the same T-line, greatly increasing the number of detectable targets by immunochromatographic techniques.

\section{Optimisation of EuNPs-Antibody Conjugates}

The optimisation of the antibody labelling amounts showed that the optimal labelling concentrations for the anti-FQs monoclonal antibody, anti-SAs monoclonal antibody and anti-TCs monoclonal antibody were 15, 25 and $20 \mu \mathrm{g} / \mathrm{ml}$ (Figures 2A-C).

The results of the optimization of fluorescent probe incorporation in the single immunochromatographic system showed that the optimal incorporation amounts of SAs-mAb-
EuNPs, FQs-mAb-EuNPs and TCs-mAb-EuNPs were 6, 4 and $5 \mathrm{ng} / \mathrm{ml}$, respectively, which can be used as a reference for the optimization of the parameters of the subsequent triple immunochromatographic system (Figure 2D).

Antibodies and labelling materials were the basis of immunological detection methods ( $\mathrm{Na}$ et al., 2020). Lanthanide, europium effectively reduces non-specific interference such as background signals, covalently couples to monoclonal antibodies by the active ester method to form detection probes that effectively indicate antibiotic residues in samples and retain satisfactory sensitivity.

\section{Optimisation of Parameters for Single-Component \\ Immunochromatography Systems}

By optimising the concentrations of artificial antigen and GAMIgG encapsulated in the $\mathrm{T}$ and $\mathrm{C}$ line positions on the $\mathrm{NC}$ membrane, it was concluded that $1.0 \mathrm{mg} / \mathrm{ml}$ of FQs-BSA and $1.5 \mathrm{mg} / \mathrm{ml}$ of GAM-IgG were used as the optimal amounts for the chromatographic system for single detection of FQs (Figure 3A). For the chromatographic system for single detection of SAs, $0.6 \mathrm{mg} / \mathrm{ml}$ of SAs-BSA and $1.5 \mathrm{mg} / \mathrm{ml}$ of GAM-IgG was used as the optimal amount for this system (Figure 3B). For chromatographic systems with single detection of TCs, $1.0 \mathrm{mg} /$ $\mathrm{ml}$ of TCs-BSA and $1.0 \mathrm{mg} / \mathrm{ml}$ of GAM-IgG was used as the optimal amount for this system (Figure 3C). The above assay 

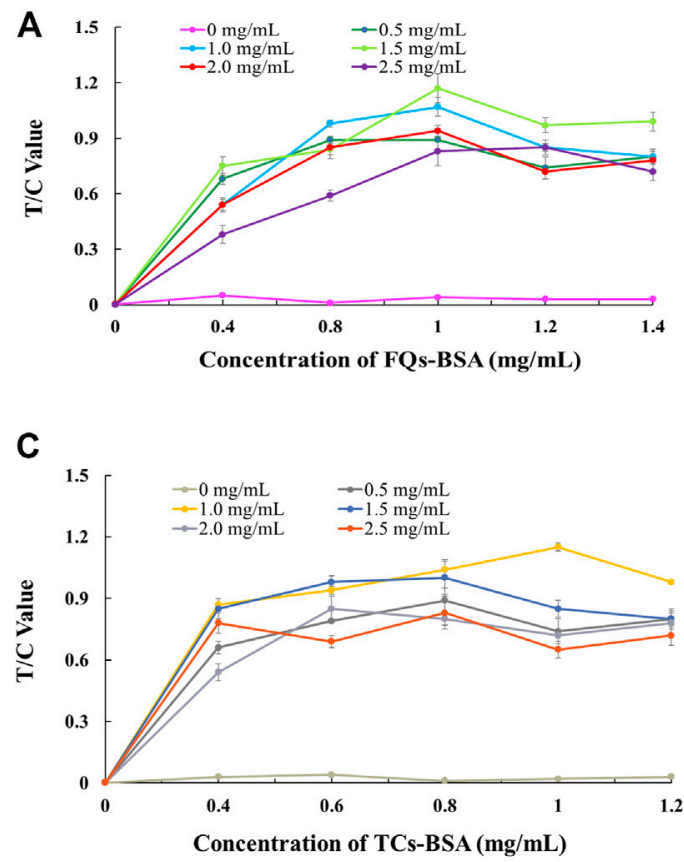
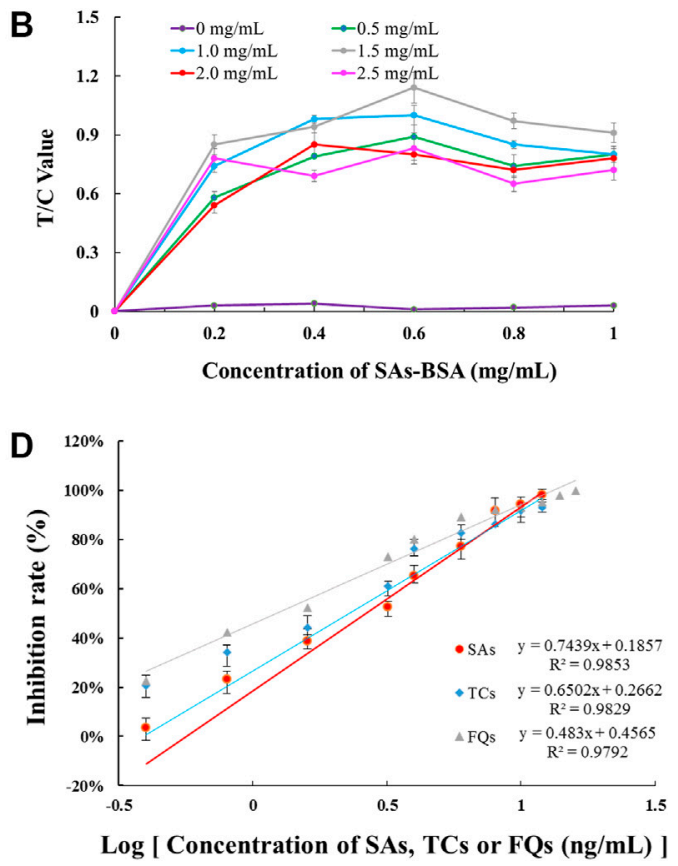

FIGURE 3|Parameter optimisation of single-EuNPs-FIA. (A) Effect of encapsulation concentrations of FQs-BSA and GAM-IgG on the detection capacity of singleEuNPs-FIA. (B) Effect of encapsulation concentrations of SAs-BSA and GAM-lgG on the detection capacity of single-EuNPs-FIA. (C) Effect of encapsulation concentrations of TCs-BSA and GAM-IgG on the detection capacity of single-EuNPs-FIA. (D) Three standard curves for single-EuNPs-FIA.

TABLE 1 | Orthogonal test to analyse the results of optimisation of L9 (3) ${ }^{3}$ on SAs-BSA concentration, GAM-IgG concentration and paddle position.

\begin{tabular}{|c|c|c|c|c|c|}
\hline Number & T-line position & SAs-BSA concentration $(\mathrm{mg} / \mathrm{ml})$ & GAM-IgG concentration ( $\mathrm{mg} / \mathrm{ml})$ & Fluorescence intensity (CPS) & T/C Value \\
\hline 1 & T1 & 0.4 & 1.0 & 24,032 & 0.21 \\
\hline 2 & $\mathrm{~T} 1$ & 0.6 & 1.5 & 25,763 & 0.23 \\
\hline 3 & $\mathrm{~T} 1$ & 0.8 & 2.0 & 26,348 & 0.24 \\
\hline 4 & $\mathrm{~T} 2$ & 0.4 & 1.5 & 10,320 & 0.18 \\
\hline 5 & $\mathrm{~T} 2$ & 0.6 & 2.0 & 11,763 & 0.20 \\
\hline 6 & $\mathrm{~T} 2$ & 0.8 & 1.0 & 12,538 & 0.35 \\
\hline 7 & T3 & 0.4 & 2.0 & 10,436 & 0.44 \\
\hline 8 & Т3 & 0.6 & 1.0 & 11,873 & 0.47 \\
\hline 9 & T3 & 0.8 & 1.5 & 12,540 & 0.64 \\
\hline
\end{tabular}

TABLE 2 | Orthogonal test to analyse the results of optimisation of L9 (3) ${ }^{3}$ on FQs-BSA concentration, GAM-lgG concentration and paddle position.

\begin{tabular}{|c|c|c|c|c|c|}
\hline Number & T-line position & FQs-BSA concentration $(\mathrm{mg} / \mathrm{ml})$ & GAM-lgG concentration $(\mathrm{mg} / \mathrm{ml})$ & Fluorescence intensity (CPS) & T/C Value \\
\hline 1 & $\mathrm{~T} 1$ & 0.8 & 1.0 & 13,654 & 0.47 \\
\hline 2 & $\mathrm{~T} 1$ & 1.0 & 1.5 & 12,098 & 0.42 \\
\hline 3 & $\mathrm{~T} 1$ & 1.2 & 2.0 & 11,012 & 0.21 \\
\hline 4 & $\mathrm{~T} 2$ & 0.8 & 1.5 & 12,987 & 0.56 \\
\hline 5 & $\mathrm{~T} 2$ & 1.0 & 2.0 & 12,653 & 0.22 \\
\hline 6 & $\mathrm{~T} 2$ & 1.2 & 1.0 & 13,964 & 0.44 \\
\hline 7 & T3 & 0.8 & 2.0 & 8,740 & 0.23 \\
\hline 8 & T3 & 1.0 & 1.0 & 9,075 & 0.41 \\
\hline 9 & T3 & 1.2 & 1.5 & 10,237 & 0.48 \\
\hline
\end{tabular}

results may provide a reference for subsequent optimization of the triple immunochromatographic system parameters. A standard curve was created by reading single test strips using an EuNPs fluorescent strip reader under optimised conditions to assess the detection sensitivity of the single test strip (Figure 3D). 
TABLE 3 | Orthogonal test to analyse the results of optimisation of L9 (3) ${ }^{3}$ on TCs-BSA concentration, GAM-IgG concentration and paddle position.

\begin{tabular}{|c|c|c|c|c|c|}
\hline Number & T-line position & TCs-BSA concentration $(\mathrm{mg} / \mathrm{ml})$ & GAM-IgG concentration $(\mathrm{mg} / \mathrm{ml})$ & Fluorescence intensity (CPS) & T/C Value \\
\hline 1 & $\mathrm{~T} 1$ & 0.8 & 0.5 & 10,765 & 0.37 \\
\hline 2 & $\mathrm{~T} 1$ & 1.0 & 1.0 & 11,796 & 0.51 \\
\hline 3 & $\mathrm{~T} 1$ & 1.2 & 1.5 & 12,780 & 0.62 \\
\hline 4 & $\mathrm{~T} 2$ & 0.8 & 1.0 & 8,653 & 0.45 \\
\hline 5 & T2 & 1.0 & 1.5 & 9,462 & 0.49 \\
\hline 6 & T2 & 1.2 & 0.5 & 10,723 & 0.58 \\
\hline 7 & T3 & 0.8 & 1.5 & 6,729 & 0.26 \\
\hline 8 & T3 & 1.0 & 0.5 & 7,862 & 0.49 \\
\hline 9 & T3 & 1.2 & 1.0 & 8,972 & 0.43 \\
\hline
\end{tabular}

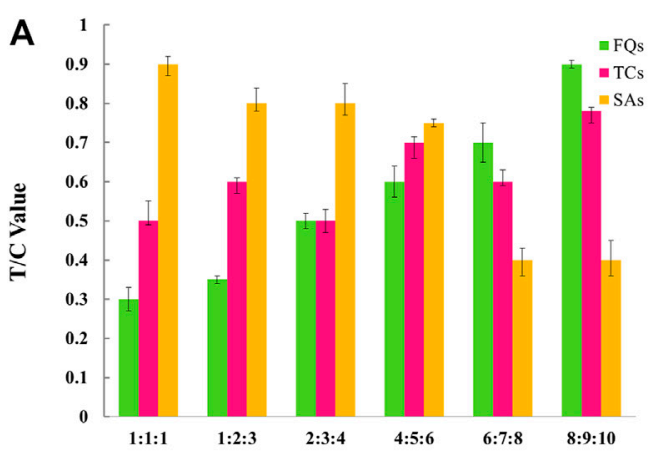

Mixed ratio of SAs, TCs and FQs fluorescent probes

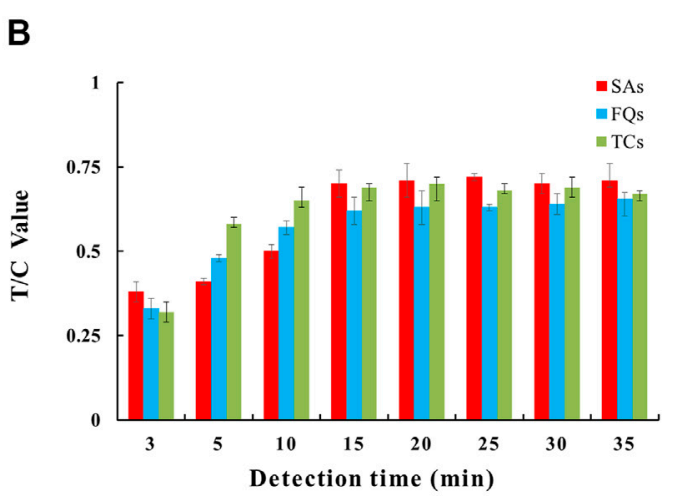

FIGURE 4 | Parameter optimisation of three-multiple-EuNPs-FIA. (A) Effect of probe mixing ratio on the detection capability of three-multiple-EuNPs-FIA. (B) Effect of reaction time duration on the detection capacity of three-multiple-EuNPs-FIA.

$\begin{array}{cccccccccccccccc}\text { A SAs (ng/mL) } & 0 & 0.1 & 0.2 & 0.4 & 0.6 & 0.8 & 1.0 & 1.2 & 2.4 & 3.2 & 4 & 8 & 10 & 12 & 14 \\ \text { FQs (ng/mL) } & 0 & 0.1 & 0.2 & 0.4 & 0.8 & 1.0 & 1.2 & 2.4 & 3.2 & 4 & 8 & 10 & 12 & 14 & 16 \\ \text { TCs (ng/mL) } & 0 & 0.1 & 0.2 & 0.3 & 0.6 & 0.9 & 1.8 & 3.2 & 4 & 8 & 10 & 12 & 14 & 16 & 18\end{array}$

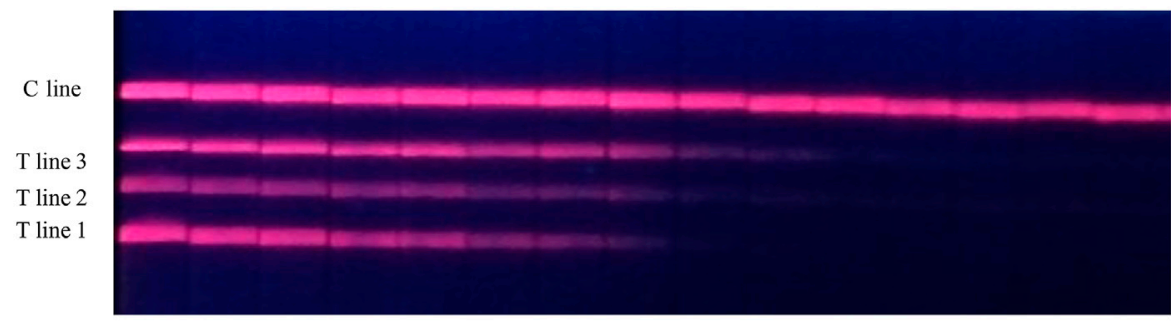

B

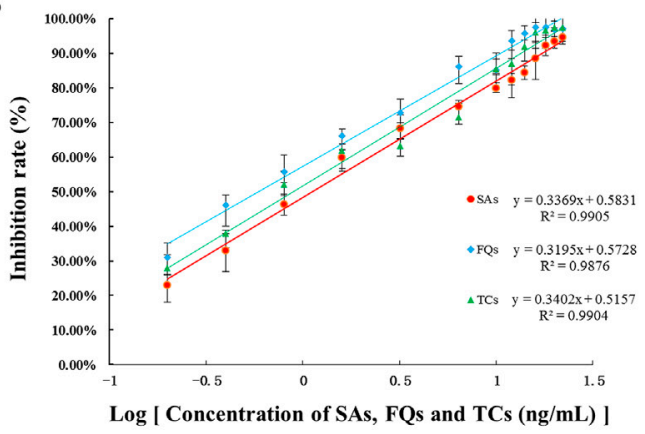

C SAs - -+++-+ $\begin{array}{lllllllll}\mathrm{SAs} & - & - & + & + & + & - & - & + \\ \mathrm{FQs} & - & + & - & + & - & + & - & + \\ \mathrm{TCs} & - & + & + & - & - & - & + & +\end{array}$

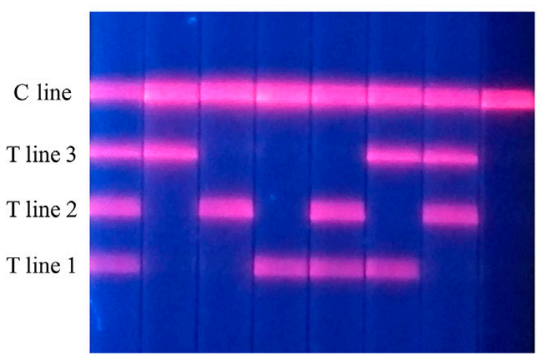

FIGURE 5 | Sensitivity and specificity analysis of three-multiple-EuNPs-FIA. (A) Simultaneous sensitivity analysis of SAs, FQs and TCs by three-multiple-EuNPSFIA. (B) The standard curve for SAs, FQs and TCs by three-multiple-EuNPs-FIA. (C) Specific analysis of three-multiple-EuNPs-FIA. 
TABLE 4 | Recovery rate determination of SAs, TCs and FQs in milk sample from three-multiple-EuNPs-FIA analysis.

\begin{tabular}{|c|c|c|c|c|}
\hline \multirow[t]{2}{*}{ Analyte } & \multirow[t]{2}{*}{ Spiked level (ng/ml) } & \multicolumn{3}{|c|}{ Intra-assay } \\
\hline & & Detected amount (ng/ml) & Recovery rate & $\operatorname{RSD}(n=3)$ \\
\hline \multirow[t]{8}{*}{ SMD } & 0.1 & 0.09 & $92.10 \%$ & $4.16 \%$ \\
\hline & 0.2 & 0.18 & $105.00 \%$ & $8.03 \%$ \\
\hline & 0.4 & 0.45 & $106.20 \%$ & $7.76 \%$ \\
\hline & 0.6 & 0.61 & $100.56 \%$ & $6.30 \%$ \\
\hline & 0.8 & 0.83 & $102.08 \%$ & $7.37 \%$ \\
\hline & 1.0 & 1.01 & $103.33 \%$ & $4.88 \%$ \\
\hline & 1.2 & 1.21 & $101.94 \%$ & $5.67 \%$ \\
\hline & 2.4 & 2.34 & $98.19 \%$ & $2.41 \%$ \\
\hline \multirow[t]{8}{*}{$\mathrm{TC}$} & 0.1 & 0.12 & $106.1 \%$ & $3.11 \%$ \\
\hline & 0.2 & 0.19 & $103.33 \%$ & $7.34 \%$ \\
\hline & 0.4 & 0.44 & $103.33 \%$ & $6.80 \%$ \\
\hline & 0.6 & 0.63 & $105.00 \%$ & $2.33 \%$ \\
\hline & 0.8 & 0.82 & $102.98 \%$ & $3.17 \%$ \\
\hline & 1.0 & 1.1 & $105.67 \%$ & $6.09 \%$ \\
\hline & 1.2 & 1.23 & $101.11 \%$ & $6.30 \%$ \\
\hline & 2.4 & 2.39 & $100.83 \%$ & $3.08 \%$ \\
\hline \multirow[t]{8}{*}{ ENR } & 0.1 & 0.12 & $103.33 \%$ & $8.10 \%$ \\
\hline & 0.2 & 0.22 & $103.33 \%$ & $8.75 \%$ \\
\hline & 0.4 & 0.45 & $105.00 \%$ & $4.86 \%$ \\
\hline & 0.6 & 0.65 & $103.33 \%$ & $3.23 \%$ \\
\hline & 0.8 & 0.87 & $99.58 \%$ & $5.82 \%$ \\
\hline & 1.0 & 1.01 & $97.33 \%$ & $3.31 \%$ \\
\hline & 1.2 & 1.13 & $97.78 \%$ & $7.34 \%$ \\
\hline & 2.4 & 2.35 & $99.31 \%$ & $2.93 \%$ \\
\hline
\end{tabular}
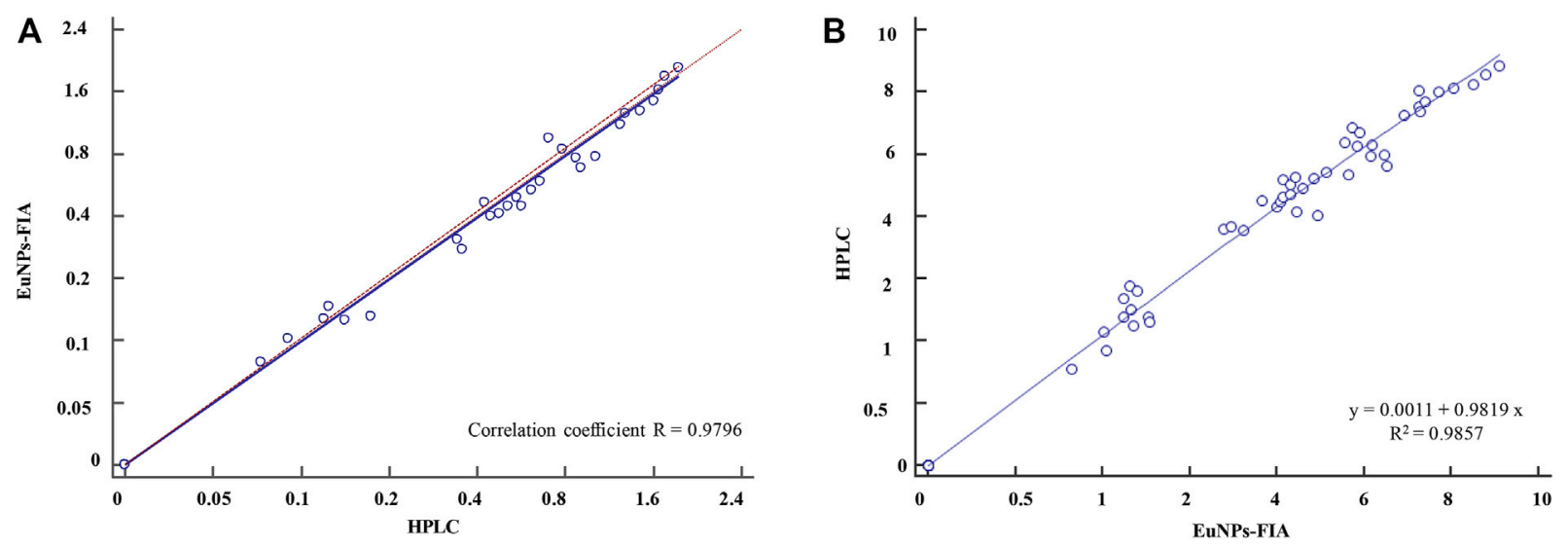

FIGURE 6 | Comparison of EuNPs-FIA and HPLC. (A) Comparative method scatter diagram of EuNPs-FIA and HPLC. (B) Passing-Bablok regression.

The advantage of the single immunochromatographic technique was that only one specific artificial antigen was encapsulated on the T-line, eliminating the need to consider the reaction between the sample and other specific substances when the liquid sample under test comes into contact with the T-line. Under optimised conditions, single-EuNPs-FIA could simultaneously detect 13 types of SAs, seven types of FQs and four types of TCs respectively, determining its potential as a competitive tool for primary mass screening in comparison to other analytical methods. However, Europium has been applied to the detection of streptomycin in milk, however, the detection was limited by a single target (Luo et al., 2020). The increase in the number of controlled compounds in medical diagnostics and ecological assays makes a single detection system inadequate for the detection needs (Supplementary Table S3).

\section{Optimization of the}

\section{Multi-Immunochromatographic System}

As the solution moves along the test strip, the concentration and interaction of the reactants in the solution changes as its initial volume is diluted (Chen et al., 2014). This affected not only the chemical equilibrium in the solution but also the binding efficiency of the test probe when it reached the T-line, so that 
TABLE 5 | Detection of SAs, TCs and FQs in egg, milk, chicken and honey samples by three-multiple-EuNPs-FIA and HPLC.

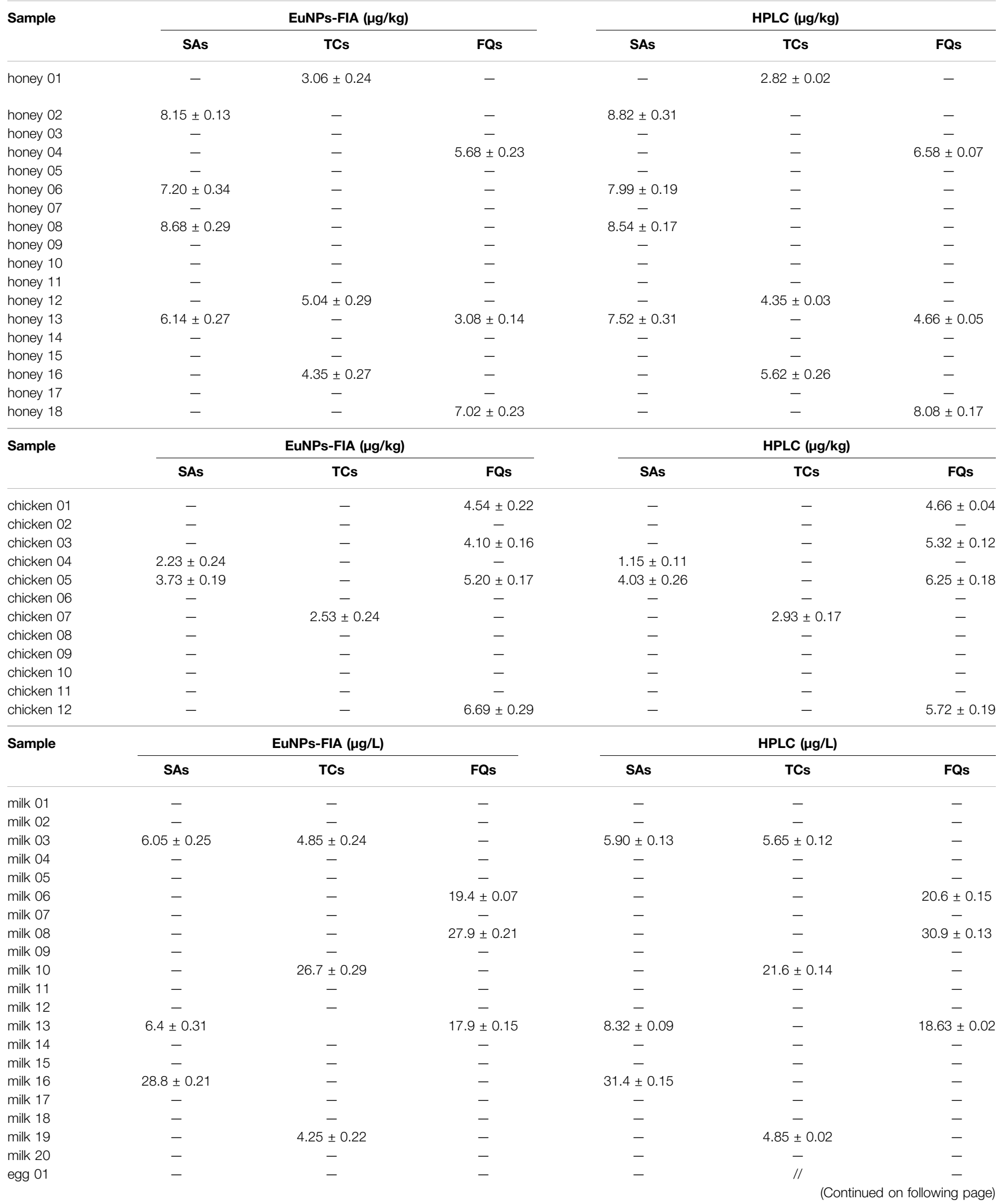


TABLE 5 | (Continued) Detection of SAs, TCs and FQs in egg, milk, chicken and honey samples by three-multiple-EuNPs-FIA and HPLC.

\begin{tabular}{|c|c|c|c|c|c|c|}
\hline \multirow[t]{2}{*}{ Sample } & \multicolumn{3}{|c|}{ EuNPs-FIA ( $\mu \mathrm{g} / \mathrm{L})$} & \multicolumn{3}{|c|}{ HPLC ( $\mu \mathrm{g} / \mathrm{L})$} \\
\hline & SAs & TCs & FQs & SAs & TCs & FQs \\
\hline egg 02 & - & - & - & - & - & - \\
\hline egg 03 & - & - & $2.01 \pm 0.22$ & - & - & $2.35 \pm 0.03$ \\
\hline egg 04 & - & - & - & & - & - \\
\hline egg 05 & $13.51 \pm 0.24$ & - & - & $15.30 \pm 0.24$ & - & - \\
\hline egg 06 & - & - & - & - & - & - \\
\hline egg 07 & - & - & - & - & - & - \\
\hline egg 08 & - & - & - & - & - & - \\
\hline egg 09 & - & $17.6 \pm 0.19$ & - & - & $14.13 \pm 0.19$ & - \\
\hline egg 10 & - & - & $6.39 \pm 0.14$ & - & - & $8.17 \pm 0.17$ \\
\hline
\end{tabular}

not only the limit of detection but also the intensity of fluorescence development changed significantly in the multiplex immunochromatography technique (Roberta et al., 2014). For multiplex immunochromatographic techniques, the localisation of several binding lines with different specific reactants was the best technical solution.

The parameters of the triple fluorescence immunochromatography system, such as artificial antigen scribing position, scribing concentration and GAM-IgG scribing concentration, were optimized by orthogonal test L9 $(3)^{3}$ analysis. The results showed that the triple fluorescence immunochromatography system was optimized when the following conditions were met: SAs-BSA at T3 and $0.8 \mathrm{mg} / \mathrm{ml}$ (Table 1), FQs-BSA at T2 and $0.8 \mathrm{mg} / \mathrm{ml}$ (Table 2), TCs-BSA at T1 and $1.2 \mathrm{mg} / \mathrm{ml}$ (Table 3). The concentration of GAM-IgG was $1.5 \mathrm{mg} / \mathrm{ml}$. The results obtained showed how the fluorescence intensity of each group of immunoreactants varies with their location. The fluorescence intensity of TCs-BSA, FQsBSA and SAs-BSA reached its maximum when they were located at $\mathrm{T} 1, \mathrm{~T} 2$ and $\mathrm{T} 3$, respectively.

The EuNPs-FIA was assembled according to the above conditions, and the parameters such as the time required for the reaction of their probe mixing ratios were optimized. The results showed that the detection capability of the three T-lines could be achieved at a mixing ratio of 6:5:4 for the three fluorescent probes of SAs, TCs and FQs (Figure 4A). The effect of reaction time on the analytical performance of the fluorescence immunochromatography system was that as the reaction time increases, the fluorescent probes achieve better binding to the antigen and the fluorescence intensity of the $\mathrm{C}$ and $\mathrm{T}$ lines gradually increases, reaching a peak at $15 \mathrm{~min}$ and remaining stable, so $15 \mathrm{~min}$ was selected as the optimal immunoreaction time for the system (Figure 4B).

\section{Specificity and Sensitivity Assessment}

The EuNPs-FIA was formally established under optimised experimental conditions, by separately testing a series of antibiotic standard solutions at different concentrations, it was observed that the fluorescence intensity on the T-line gradually diminished until it disappeared as the concentration of the standard increased, thus obtaining a cut-off value for the monitoring system. When using EuNPs-FIA under the same conditions, the T-line fluorescence intensity disappears at standard concentrations of 4.0, 3.2 and $2.4 \mathrm{ng} / \mathrm{ml}$ and allows for simultaneous detection of all three antibiotics (Figure 5A). Based on the cut-off values, a standard curve was created by reading the test strips using an EuNPs fluorescent strip reader thereby creating a standard curve (Figure 5B), expressing the relationship between inhibition and the logarithm of the antibiotic concentration and calculating the cross-reactivity (CR) between each antibiotic (Supplementary Table S1-S3). The high cross-reactivity between antibiotics of the same class, due to the same parent nucleus structure, offered the possibility of simultaneous detection of multiple targets to be tested.

The specificity of the method was assessed by calculating the cross-reactivity between 13 types of SAs, four types of TCs and seven types of FQs separately, and the results showed that there was a significant cross-reactivity of the screened SAs-mAb for 13 types of SAs, a significant cross-reactivity of the screened TCs$\mathrm{mAb}$ for four types of TCs and a significant cross-reactivity of the screened FQs-mAb for seven types of FQs cross-reactivity. The three monoclonal antibodies were shown to be group-specific monoclonal antibody and the EuNPs-FIA allowed the simultaneous detection of 24 structurally different antibiotic residues (Supplementary Figure S5). And there was no cross-reactivity between the three families of antibiotics (Figure 5C), indicating that the three classes of antibiotics do not affect each other. The class specificity of the three monoclonal antibodies was excellent.

\section{Spiked Recovery Tests and Actual Sample Analysis}

The accuracy and precision of the method was evaluated by spiked recovery experiments. Different concentrations of analytes were added to HPLC-validated negative blank milk samples and then assayed by EuNPs-FIA. The results showed (Table 4) that the mean recoveries of the three types of mixed reference analytes ranged from 92.1 to $106.2 \%$ at spiked concentrations of $0.1-2.4 \mathrm{ng} / \mathrm{ml}$ with a relative standard deviation of less than $8.75 \%$. The assay results were validated by using HPLC with correlation coefficients above 0.97 (Figure 6A).

To further validate the established method, 60 different samples purchased from the whole province of Zhejiang were determined using EuNPs-FIA and HPLC. The results demonstrated a satisfactory agreement between the detection values of EuNPs-FIA and HPLC $\left(R^{2}>0.98\right)$ (Figure 6B). This indicated that the EuNPs-FIA can be used for the analysis of real samples (Table 5). Therefore, it was effective for controlling the potential risk of antibiotic residues in food and could be used for direct dilution testing of milk samples with a detection time of $15 \mathrm{~min}$, no loss of detection sensitivity and almost complete recovery of the added target analytes. 


\section{CONCLUSION}

In this study, artificial antigens were prepared by designing and synthesizing the parent nucleus structures of each of SAs, TCs and FQs, coupling the parent nucleus structure antigens of FQs, SAs and TCs with carrier proteins by carbodiimide and $\mathrm{N}$-hydroxysuccinimide-activated ester methods, respectively, and immunising mice to obtain herd immune monoclonal antibodies. The EuNPs-FIA detection system was constructed by combining the novel fluorescent nanomaterial europium, immunolateral flow test paper and monoclonal antibodies. It not only resolved the problem of low sensitivity of traditional detection methods, but also enabled the detection of almost an entire class of antibiotic drug residues by a single test line. The combination of the three T-lines was capable of detecting four types of TCs, seven types of FQs and 13 types of SAs simultaneously, covering 24 antibiotic residues in different structural forms. The number of compounds that can be detected and controlled in food safety and ecological monitoring has been increased, enabling public environmental safety to be ensured. The detection results were highly correlated with those of HPLC. The method therefore exhibits high sensitivity, good accuracy and reliability and satisfactory selectivity. It could contribute to the detection and monitoring of sulphonamide, tetracycline and fluoroquinolone antibiotic residues in food and to the monitoring of the quality of the environment in which people live. Currently, we are investigating the use of a population immunogenic monoclonal antibody on test strips to recognise more different classes of target to be tested, enabling the detection of multiple classes of targets in a single T-line. We hope that this multiplex test strip analysis will be useful in maintaining food safety.

\section{REFERENCES}

Abafe, O. A., Gatyeni, P., and Matika, L. (2020). A Multi-Class Multi-Residue Method for the Analysis of Polyether Ionophores, Tetracyclines and Sulfonamides in Multi-Matrices of Animal and Aquaculture Fish Tissues by Ultra-high Performance Liquid Chromatography Tandem Mass Spectrometry. Food Additives \& Contaminants: A 37, 438-450. doi:10.1080/ 19440049.2019.1705399

Ashuo, A., Zou, W., Fu, J., Yang, T., Yu, L., Liu, W., et al. (2020). High Throughput Detection of Antibiotic Residues in Milk by Time-Resolved Fluorescence Immunochromatography Based on QR Code. Food Additives \& Contaminants: Part A 37, 1481-1490. doi:10.1080/19440049.2020.1778192

Bartosh, A. V., Sotnikov, D. V., Hendrickson, O. D., Zherdev, A. V., and Dzantiev, B. B. (2020). Design of Multiplex Lateral Flow Tests: A Case Study for Simultaneous Detection of Three Antibiotics. Biosensors 10, 17. doi:10.3390/bios10030017

Ben, Y., Hu, M., Zhang, X., Wu, S., Wong, M. H., Wang, M., et al. (2020). Efficient Detection and Assessment of Human Exposure to Trace Antibiotic Residues in Drinking Water. Water Res. 175, 115699. doi:10.1016/j.watres.2020.115699

Booth, A., Aga, D. S., and Wester, A. L. (2020). Retrospective Analysis of the Global Antibiotic Residues that Exceed the Predicted No Effect Concentration for Antimicrobial Resistance in Various Environmental Matrices. Environ. Int. 141, 105796. doi:10.1016/j.envint.2020.105796

Castillo-García, M. L., Aguilar-Caballos, M. P., and Gómez-Hens, A. (2015). A Europium- and Terbium-Coated Magnetic Nanocomposite as Sorbent in Dispersive Solid Phase Extraction Coupled with Ultra-high Performance

\section{DATA AVAILABILITY STATEMENT}

The raw data supporting the conclusion of this article will be made available by the authors, without undue reservation.

\section{ETHICS STATEMENT}

The animal study was reviewed and approved by Animal Care and Use Committee of Hangzhou Normal University (Hangzhou, China).

\section{AUTHOR CONTRIBUTIONS}

MZ designed the experiments, YW, EC, and YX conducted experiments and analyzed data. YW and BM wrote the main manuscript text and prepared all figures and tables. ML completed the revision of the manuscript text. All authors reviewed the manuscript.

\section{FUNDING}

The work was supported by the Key Research and Development Program of Zhejiang Province (No. 2021C02060).

\section{SUPPLEMENTARY MATERIAL}

The Supplementary Material for this article can be found online at: https://www.frontiersin.org/articles/10.3389/fchem.2021.793355/ full\#supplementary-material

Liquid Chromatography for Antibiotic Determination in Meat Samples. J. Chromatogr. A 1425, 73-80. doi:10.1016/j.chroma.2015.11.048

Chen, H., Zhang, X., Jin, Z., Huang, L., Dan, H., Xiao, W., et al. (2020). Differential Diagnosis of PRV-Infected versus Vaccinated Pigs Using a Novel EuNPs-Virus Antigen Probe-Based Blocking Fluorescent Lateral Flow Immunoassay. Biosens. Bioelectron. 155, 112101. doi:10.1016/ j.bios.2020.112101

Chen, M., Wen, K., Tao, X., Ding, S., Xie, J., Yu, X., et al. (2014). A Novel Multiplexed Fluorescence Polarisation Immunoassay Based on a Recombinant Bi-specific Single-Chain Diabody for Simultaneous Detection of Fluoroquinolones and Sulfonamides in Milk. Food Additives \& Contaminants: Part A 31, 1959-1967. doi:10.1080/19440049.2014.976279

Chen, Y., Chen, Q., Han, M., Liu, J., Zhao, P., He, L., et al. (2016). Near-infrared Fluorescence-Based Multiplex Lateral Flow Immunoassay for the Simultaneous Detection of Four Antibiotic Residue Families in Milk. Biosens. Bioelectron. 79, 430-434. doi:10.1016/j.bios.2015.12.062

Chen, Y., Cui, K., Huang, Q., Guo, Z., Huang, Y., Yu, K., et al. (2020). Comprehensive Insights into the Occurrence, Distribution, Risk Assessment and Indicator Screening of Antibiotics in a Large Drinking Reservoir System. Sci. Total Environ. 716, 137060. doi:10.1016/j.scitotenv.2020.137060

Chen, Y., Liu, L., Xu, L., Song, S., Kuang, H., Cui, G., et al. (2017). Gold Immunochromatographic Sensor for the Rapid Detection of Twenty-Six Sulfonamides in Foods. Nano Res. 10, 2833-2844. doi:10.1007/s12274-017-1490-x

El Kojok, H., El Darra, N., Khalil, M., Capo, A., Pennacchio, A., Staiano, M., et al. (2020). Fluorescence Polarization Assay to Detect the Presence of Traces of Ciprofloxacin. Sci. Rep. 10, 4550. doi:10.1038/S41598-020-61395-3 
Feng, L., Cheng, Y., Zhang, Y., Li, Z., Yu, Y., Feng, L., et al. (2020). Distribution and Human Health Risk Assessment of Antibiotic Residues in Large-Scale Drinking Water Sources in Chongqing Area of the Yangtze River. Environ. Res. 185, 109386. doi:10.1016/j.envres.2020.109386

Galarini, R., Diana, F., Moretti, S., Puppini, B., Saluti, G., and Persic, L. (2014). Development and Validation of a New Qualitative ELISA Screening for Multiresidue Detection of Sulfonamides in Food and Feed. Food Control 35, 300-310. doi:10.1016/j.foodcont.2013.07.014

GB31650-2019 (2019). National Food Safety Standard Maximum Residue Limits for Veterinary Drugs in Foods. Beijing: Standards Press of China.

Gong, Y., Zhang, M., Wang, M., Chen, Z., and Xi, X. (2014). Development of Immuno-Based Methods for Detection of Melamine. Arab J. Sci. Eng. 39, 5315-5324. doi:10.1007/s13369-014-1116-5

Hoffmann, H., Baldofski, S., Hoffmann, K., Flemig, S., Silva, C. P., Esteves, V. I., et al. (2016). Structural Considerations on the Selectivity of an Immunoassay for Sulfamethoxazole. Talanta 158, 198-207. doi:10.1016/j.talanta.2016.05.049

Hu, S., Li, D., Huang, Z., Xing, K., Chen, Y., Peng, J., et al. (2018). Ultra-sensitive Method Based on Time-Resolved Fluorescence Immunoassay for Detection of Sulfamethazine in Raw Milk. Food Agric. Immunol. 29, 1137-1149. doi:10.1080/09540105.2018.1520816

Huang, D., Ying, H., Jiang, D., Liu, F., Tian, Y., Du, C., et al. (2020). Rapid and Sensitive Detection of Interleukin-6 in Serum via Time-Resolved Lateral Flow Immunoassay. Anal. Biochem. 588, 113468. doi:10.1016/j.ab.2019.113468

Jin, G., Wu, X., Cui, G., Liu, L., Kuang, H., and Xu, C. (2020). Development of an Ic-ELISA and Immunochromatographic Strip Assay for the Detection of Diacetoxyscirpenol in Rice. ACS omega 5, 17876-17882. doi:10.1021/acsomega.9b02496

Kong, M., Bu, Y.-Q., Zhang, Q., Zhang, S.-H., Xing, L.-Q., Gao, Z.-Q., et al. (2021). Distribution, Abundance, and Risk Assessment of Selected Antibiotics in a Shallow Freshwater Body Used for Drinking Water, China. J. Environ. Manage. 280, 111738. doi:10.1016/J.JENVMAN.2020.111738

Konstantinidis, T., Tsigalou, C., Karvelas, A., Stavropoulou, E., Voidarou, C., and Bezirtzoglou, E. (2020). Effects of Antibiotics upon the Gut Microbiome: A Review of the Literature. Biomedicines 8, 502. doi:10.3390/biomedicines 8110502

Kotwani, A., Joshi, J., and Kaloni, D. (2021). Pharmaceutical Effluent: a Critical Link in the Interconnected Ecosystem Promoting Antimicrobial Resistance. Environ. Sci. Pollut. Res. 28, 32111-32124. doi:10.1007/S11356-021-14178-W

Liang, X., Li, C., Zhu, J., Song, X., Yu, W., Zhang, J., et al. (2019). Dihydropteroate Synthase Based Sensor for Screening Multi-Sulfonamides Residue and its Comparison with Broad-specific Antibody Based Immunoassay by Molecular Modeling Analysis. Analytica Chim. Acta 1050, 139-145. doi:10.1016/j.aca.2018.11.005

Lin, B., Zhang, T., Xin, X., Wu, D., Huang, Y., Liu, Y., et al. (2019). Europium(III) Modified Silicone Nanoparticles for Ultrasensitive Visual Determination of Tetracyclines by Employing a Fluorescence Color Switch. Microchim Acta 186, 186. doi:10.1007/s00604-019-3557-8

Lin, X. L., Rao, h., and Xiong, Y. H. (2010). Rapid Detection of Sulfadimidine Residue in Food by Colloidal Gold Strips. Chin. J. Food Sci. 24, 366-369. CNKI: SUN:SPKX.0.2010-24-081.

Luo, M., Xing, K., Guo, Z., Guo, D., Lai, W., and Peng, J. (2020). Sensitive Immunoassays Based on a Monoclonal Antibody for Detection of Marbofloxacin in Milk. J. Dairy Sci. 103, 7791-7800. doi:10.3168/JDS.2019-18108

Majdinasab, M., Mitsubayashi, K., and Marty, J. L. (2019). Optical and Electrochemical Sensors and Biosensors for the Detection of Quinolones. Trends Biotechnol. 37, 898-915. doi:10.1016/j.tibtech.2019.01.004

Na, G., Hu, X., Yang, J., Sun, Y., Kwee, S., Tang, L., et al. (2020). Colloidal Gold-Based Immunochromatographic Strip Assay for the Rapid Detection of Bacitracin Zinc in Milk. Food Chem. 327, 126879. doi:10.1016/j.foodchem.2020.126879

Rashid, A., Mazhar, S. H., Zeng, Q., Kiki, C., Yu, C.-P., and Sun, Q. (2020). Simultaneous Analysis of Multiclass Antibiotic Residues in Complex Environmental Matrices by Liquid Chromatography with Tandem Quadrupole Mass Spectrometry. J. Chromatogr. B 1145, 122103. doi:10.1016/J.JCHROMB.2020.122103

Soh, J. H., Chan, H.-M., and Ying, J. Y. (2020). Strategies for Developing Sensitive and Specific Nanoparticle-Based Lateral Flow Assays as point-of-care Diagnostic Device. Nano Today 30, 100831. doi:10.1016/j.nantod.2019.100831

Sun, Y., Xie, J., Peng, T., Wang, J., Xie, S., Yao, K., et al. (2017). A New Method Based on Time-Resolved Fluoroimmunoassay for the Detection of Streptomycin in Milk. Food Anal. Methods 10, 2262-2269. doi:10.1007/s12161-017-0797-2

Suo, D., Wang, P., Xiao, Z., Zhang, S., Zhuang, H., Li, Y., et al. (2019). Multiresidue Determination of 27 Sulfonamides in Poultry Feathers and its Application to a Sulfamethazine Pharmacokinetics Study on Laying Hen Feathers and
Sulfonamide Residue Monitoring on Poultry Feathers. J. Agric. Food Chem. 67, 11236-11243. doi:10.1021/acs.jafc.9b02782

Wang, J., Meng, H.-M., Chen, J., Liu, J., Zhang, L., Qu, L., et al. (2019). Quantum Dot-Based Lateral Flow Test Strips for Highly Sensitive Detection of the Tetanus Antibody. ACS Omega 4, 6789-6795. doi:10.1021/ acsomega.9b00657.s00110.1021/acsomega.9b00657

Wang, Z., Sun, Y., Liang, D., Zeng, Y., He, S., Mari, G. M., et al. (2020). Highly Sensitive Chromatographic Time-Resolved Fluoroimmunoassay for Rapid Onsite Detection of Streptomycin in Milk. J. Dairy Sci. 103, 8750-8760. doi:10.3168/JDS.2020-18393

Wei, W., He, J., Wang, Y., and Kong, M. (2019). Ratiometric Method Based on Silicon Nanodots and Eu3+ System for Highly-Sensitive Detection of Tetracyclines. Talanta 204, 491-498. doi:10.1016/j.talanta.2019.06.036

Wu, Y.-Y., Huang, P., and Wu, F.-Y. (2020). A Label-free Colorimetric Aptasensor Based on Controllable Aggregation of AuNPs for the Detection of Multiplex Antibiotics. Food Chem. 304, 125377. doi:10.1016/j.foodchem.2019.125377

Xie, Y., Zhu, Z., Wang, J., Zhang, L., Zhang, Z., Lu, H., et al. (2018). Ten-Day Quadruple Therapy Comprising Low-Dose Rabeprazole, Bismuth, Amoxicillin, and Tetracycline Is an Effective and Safe First-Line Treatment for Helicobacter pylori Infection in a Population with High Antibiotic Resistance: a Prospective, Multicenter, Randomized, Parallel-Controlled Clinical Trial in China. Antimicrob. Agents Chemother. 62, e00432-18. doi:10.1128/AAC.00432-18

Xu, Y., Ma, B., Chen, E., Yu, X., Sun, C., and Zhang, M. (2020). Functional UpConversion Nanoparticle-Based Immunochromatography Assay for Simultaneous and Sensitive Detection of Residues of Four Tetracycline Antibiotics in Milk. Front. Chem. 8, 759. doi:10.3389/fchem.2020.00759

Xu, Z.-L., Wang, Q., Lei, H.-T., Eremin, S. A., Shen, Y.-D., Wang, H., et al. (2011). A Simple, Rapid and High-Throughput Fluorescence Polarization Immunoassay for Simultaneous Detection of Organophosphorus Pesticides in Vegetable and Environmental Water Samples. Analytica Chim. Acta 708, 123-129. doi:10.1016/j.aca.2011.09.040

Yang, L., Ni, H., Li, C., Zhang, X., Wen, K., Ke, Y., et al. (2019). Development of a Highly Specific Chemiluminescence Aptasensor for Sulfamethazine Detection in Milk Based on In Vitro Selected Aptamers. Sensors Actuators B: Chem. 281, 801-811. doi:10.1016/j.snb.2018.10.143

Ye, Y., Wu, T., Jiang, X., Cao, J., Ling, X., Mei, Q., et al. (2020). Portable Smartphone-Based QDs for the Visual Onsite Monitoring of Fluoroquinolone Antibiotics in Actual Food and Environmental Samples. ACS Appl. Mater. Inter. 12, 14552-14562. doi:10.1021/acsami.9b23167

Zhang, Y., Duan, B., Bao, Q., Yang, T., Wei, T., Wang, J., et al. (2020). Aptamermodified Sensitive Nanobiosensors for the Specific Detection of Antibiotics. J. Mater. Chem. B 8, 8607-8613. doi:10.1039/d0tb01441a

Zhou, J., Zhu, K., Xu, F., Wang, W., Jiang, H., Wang, Z., et al. (2014). Development of a Microsphere-Based Fluorescence Immunochromatographic Assay for Monitoring Lincomycin in Milk, Honey, Beef, and Swine Urine. J. Agric. Food Chem. 62, 12061-12066. doi:10.1021/jf5029416

Zou, R., Chang, Y., Zhang, T., Si, F., Liu, Y., Zhao, Y., et al. (2019). Up-Converting Nanoparticle-Based Immunochromatographic Strip for Multi-Residue Detection of Three Organophosphorus Pesticides in Food. Front. Chem. 7, 16. doi:10.3389/fchem.2019.00018

Conflict of Interest: The authors declare that the research was conducted in the absence of any commercial or financial relationships that could be construed as a potential conflict of interest.

Publisher's Note: All claims expressed in this article are solely those of the authors and do not necessarily represent those of their affiliated organizations, or those of the publisher, the editors, and the reviewers. Any product that may be evaluated in this article, or claim that may be made by its manufacturer, is not guaranteed or endorsed by the publisher.

Copyright (๑) 2021 Wang, Ma, Liu, Chen, Xu and Zhang. This is an open-access article distributed under the terms of the Creative Commons Attribution License (CC $B Y)$. The use, distribution or reproduction in other forums is permitted, provided the original author(s) and the copyright owner(s) are credited and that the original publication in this journal is cited, in accordance with accepted academic practice. No use, distribution or reproduction is permitted which does not comply with these terms. 